Société d'histoire de la révolution de 1848 et des

révolutions du XIXe siècle

$50 \mid 2015$

Sociétés et forces de sécurité au XIXe siècle

\title{
Antoine LILTI, Figures publiques. L'invention de la célébrité, 1750-1850
}

Paris, Fayard, 2014, 430 p. ISBN : 978-2-213-68238-9. 24 euros.

Jean-Clément Martin

\section{(2) OpenEdition}

Journals

Édition électronique

URL : http://journals.openedition.org/rh19/4835

DOI : 10.4000/rh19.4835

ISSN : $1777-5329$

Éditeur

La Société de 1848

\section{Édition imprimée}

Date de publication : 1 juillet 2015

Pagination : 201-203

ISSN : 1265-1354

\section{Référence électronique}

Jean-Clément Martin, «Antoine LILTI, Figures publiques. L'invention de la célébrité, 1750-1850 », Revue d'histoire du XIXe siècle [En ligne], 50 | 2015, mis en ligne le 01 juillet 2015, consulté le 23 septembre 2020. URL : http://journals.openedition.org/rh19/4835 ; DOI : https://doi.org/10.4000/rh19.4835

Ce document a été généré automatiquement le 23 septembre 2020

Tous droits réservés 


\section{Antoine LILTI, Figures publiques. L'invention de la célébrité, 1750-1850}

Paris, Fayard, 2014, 430 p. ISBN : 978-2-213-68238-9. 24 euros.

Jean-Clément Martin

\section{RÉFÉRENCE}

Antoine LILTI, Figures publiques. L'invention de la célébrité, 1750-1850, Paris, Fayard, 2014, 430 p. ISBN : 978-2-213-68238-9. 24 euros.

1 Le XVIII ${ }^{e}$ siècle a été inventif : aux saints et aux rois, il a ajouté les hommes illustres dont l'ultime demeure est le Panthéon, ainsi que les hommes célèbres de la nation destinés à être collationnés dans les dictionnaires, un peu plus tardivement les femmes auteurs recensées comme il se doit par l'une d'entre elles; plus que tout, il a inventé « la célébrité » en tant que telle, produit de consommation collective immédiat. C'est l'objet de ce livre que de montrer que la « publicité » qui prend forme dans le milieu du siècle, si l'on suit les analyses classiques de Jürgen Habermas, s'est accompagnée d'une pratique déroutante si l'on attend que ce soit la rationalité et l'esprit critique qui aient pu profiter de cette nouvelle forme d'échange, puisque c'est la célébrité, forme abâtardie de la gloire, qui influence les foules moutonnières, dans une caricature de la démocratie.

Dans ce livre enraciné dans les meilleures traditions de l'histoire sociale, attentives aux études de cas comme aux grandes tendances collectives, l'auteur, connu pour son étude précédente du «monde des salons » et de la mondanité parisienne au XVIII ${ }^{\mathrm{e}}$ siècle, continue sa lecture, roborative, des pratiques sociales du passé en les confrontant aux usages très contemporains. Dès les premières lignes, le ton est donné puisque MarieAntoinette est comparée à Lady Di à propos du tournage du film de Sofia Coppola. L'anachronisme est revendiqué comme méthode, puisque la notion même de célébrité permet de renouveler la compréhension de la société du XVIII ${ }^{\mathrm{e}}$ siècle comme de 
comprendre à quel point la «pipolisation » contemporaine copie ce qui se faisait deux siècles plus tôt.

3 L'introduction distingue gloire, réputation et célébrité, définie par la jolie formule: « une personne célèbre est connue par des gens qui n'ont aucune raison d'avoir un avis sur elle ». L'ambivalence de cette catégorisation, démocratique et vulgaire, fondée sur l'imitation collective et accessible au plus grand nombre, fonctionnant à la curiosité au point d'indisposer ceux-là même qui en sont l'objet et qui, éventuellement, cherchent à en profiter-, est le cœur de la démonstration et en représente tout l'intérêt, rompant avec des conceptions trop simplistes de l'adoration ou de la manipulation, souvent requises pour expliquer les mouvements de foules. La notion met aussi en exergue l'inversion du privé et du public, comme le dit bien l'auteur, puisque c'est l'intime qui est dévoilé et recherché. Ainsi est-il possible d'apprécier autrement l'engouement pour les romans épistolaires (La Nouvelle Héloïse ou Paméla) qui eurent tant de succès parce qu'ils révélaient cette omniprésence du « moi » qui unifiait les esprits en Europe. Les limites de l'ouvrage sont enfin présentées avec souplesse, puisque l'auteur est bien conscient de s'inscrire dans l'espace-temps flou que l'on appelle « modernité » sans pouvoir le circonscrire, tout en étant assuré de l'intérêt du mot. Ainsi ce livre d'histoire sociale est aussi et surtout un essai, avec l'intérêt et les risques du genre.

4 Sur un siècle, le lecteur est invité à suivre les figures publiques qui des années 1750 aux environs de 1850 ont marqué l'opinion européenne et américaine. L'espace et le temps couverts sont considérables pour rendre compte d'un seul phénomène : la célébrité liée à la modernité. Voltaire et Rousseau sont les premières personnalités suivies dans cette "société du spectacle» toute aussi frivole, inconséquente et indécente que celle que nous subissons. Mais si Voltaire sut en tirer profit, Rousseau en souffrit; outre le fait que l'un et l'autre furent concurrencés par des célébrités éphémères, comme l'acteur comique Janot. Il n'est évidemment pas étonnant que le monde du théâtre fournisse le gros contingent de " vedettes ", comme Garrick à Londres ou $\mathrm{M}^{\text {elle }}$ Clairon à Paris, dont certaines réussissent à profiter de la confusion entre leur personne et le personnage qui les a rendues célèbres et font fortune, avec le risque que la surexposition qui en résulte dévoile des penchants contestés ou dépossède le bénéficiaire de sa propre personnalité. Rousseau en est le meilleur exemple, devenu "Jean-Jacques ", il devient un «spectacle» pour un public ignorant l'œuvre de l'homme! Indiscutablement, l'auteur tient là le cas le plus réussi, qui s'expose lui-même, avant de réfléchir sur la souffrance qu'il ressent de cette situation et d'en tirer matière à un livre.

5 L'admirateur ou l'admiratrice, le «fan » comme l'auteur l'écrit avec raison, envahit littéralement la vie privée de la célébrité, ce que certains comme Talma semblèrent supporter, voire revendiquer comme Laurence Sterne, ce que d'autres trouvèrent insupportable, puisque la célébrité peut déboucher aussi bien sur la fascination que sur la dérision. C'est toute une industrie qui naît de cette révolution sociale, illustrée par la presse spécialisée, par les portraitistes et les caricaturistes, comme par les musées de cire, dont le prototype est celui de Curtius et de sa «nièce» Madame Tussaud. La nouveauté n'avait pas échappé à des penseurs comme le français Duclos, historiographe royal, et l'anglais Johnson, publiciste lui-même devenu célèbre.

6 Si les célébrités de la fin du XVIII ${ }^{e}$ siècle apparaissent dans le livre, de Marie-Antoinette à Cartouche, Mirabeau, Marat et Charlotte Corday sont les grandes figures de la Révolution, riche pourtant en personnages remarqués, en héros suivis par des foules - 
à l'exception de Washington qui fut meurtri de sa chute de popularité -, avant que Bonaparte ne remporte la palme, notamment pour avoir su mettre en œuvre la machine à célébrer. Comme l'écrivit $\mathrm{M}^{\mathrm{me}}$ de Staël : «c'était la première fois, depuis la Révolution, qu'on entendait un nom propre dans toutes les bouches ». Napoléon réalise les «noces du pouvoir et de la célébrité », tout en préservant son espace privé de tout débordement. Si l'auteur éclaire avec pertinence les difficultés qu'il y a pour ces grands personnages à contrôler les dérives possibles de la célébrité, il ne souligne sans doute pas autant que la chose l'aurait mérité, l'un des moteurs de la période révolutionnaire : le choc des personnalités, leur besoin d'avoir des soutiens et des fidèles pour agir dans ce qui est convenu d'appeler l'espace public démocratique. La mention de Robespierre, réticent à la popularité tout en la cherchant, frustre ici le lecteur, d'autant que la personnalité de Napoléon a fait éclater le cadre de l'enquête. Non seulement celui-ci est célèbre, mais il incarne même un nouveau modèle d'humanité, ce dont le romantisme ne se consolera pas, en même temps que l'époque banalise définitivement la célébrité.

7 Le XIX ${ }^{e}$ siècle mêle en effet les exemples disparates, de Byron à Liszt, en passant par Beethoven et Chateaubriand, mais aussi par les médiocres célébrités d'un jour illustrées par l'écrivain Canalis du roman de Balzac, Modeste Mignon, dont le cas illustre aussi les réserves que le public pouvait exprimer alors même qu'il semblait crédule. Dans ce «nouvel âge », c'est la personnalité de Garibaldi qui se dégage, figure inclassable qui déplace un demi-million de Londoniens lorsqu'il vient en Angleterre. Mais l'époque qui voit l'œuvre d'art entrer dans la « reproduction technique ", comme l'avait dit Walter Benjamin (qui n'est pas cité), modifie le rapport à la célébrité dorénavant reproductible par les circuits commerciaux qui en changent le sens. Si le principe qui est au cœur de l'ouvrage est toujours actif, la démonstration est modifiée alors que la conclusion élude les dérives de la célébrité que les régimes totalitaires pratiquèrent au $\mathrm{XX}^{\mathrm{e}}$ siècle. $\mathrm{La}$ célébrité a bifurqué vers le charisme, ce que Napoléon avait expérimenté et ce qu'il aurait fallu examiner davantage. Cela ne remet pas en cause l'intérêt du livre, ni son usage rafraîchissant de l'anachronisme, mais cela rappelle que la plus brillante interprétation du passé ne peut pas s'affranchir des contextes et que c'est au travers des négociations réalisées à chaque époque que les mécanismes sociaux trouvent leur développement et leur mutation, rendant toujours difficile l'emploi de notions qui pourraient sembler intemporelles. En nous obligeant à chercher ce qui nous rapproche et nous différencie du XVIII ${ }^{e}$ siècle des célébrités, Antoine Lilti rappelle ce que nous apprend l'épaisseur de l'Histoire, il faut l'en remercier. 